\title{
Genu valgum and primary hyperparathyroidism in children
}

\author{
Ramkumar S, Devasenathipathy Kandasamy, Vijay MK, \\ Madhavi Tripathi, Jyotsna VP
}

\begin{abstract}
Introduction: Bony deformity due to primary hyperparathyroidism is a rare entity in children. Case Series: We describe two children who presented with genu valgum to the Endocrine Department. Ten children with primary hyperparathyroidism presenting with genu valgum have been reported in literature and have been reviewed by us. Biochemical investigations revealed parathyroid hormone dependent hypercalcemia despite a deficiency of vitamin $D$ in both children. A single parathyroid adenoma was identified by ultrasonography and (99m) Tcsestamibi (MIBI) scan. Both children underwent resection of the solitary parathyroid lesion which was confirmed as adenoma by histopathological examination. All cases reported in literature had solitary parathyroid adenoma and had onset around puberty consistent with our observation that pubertal growth spurt is responsible for the occurrence of genu valgum
\end{abstract}

Ramkumar $\mathrm{S}^{1}$, Devasenathipathy Kandasamy², Vijay $\mathrm{MK}^{3}$, Madhavi Tripathi ${ }^{4}$, Jyotsna VP 5

Affiliations: ${ }^{1}$ Senior Resident, Department of Endocrinology and Metabolism, All India Institute of Medical Sciences, New Delhi, India; ${ }^{2}$ Assistant Professor, Department of Radiology, All India Institute of Medical Sciences, New Delhi, India; ${ }^{3}$ Senior Resident, Department of Pathology, All India Institute of Medical Sciences, New Delhi, India; ${ }^{4}$ Assistant Professor, Department of Nuclear Medicine, All India Institute of Medical Sciences, New Delhi, India; ${ }^{5}$ Additional Professor, Department of Endocrinology and Metabolism, All India Institute of Medical Sciences, New Delhi

Corresponding Author: Dr. Viveka P. Jyotsna, Additional Professor, Department of Endocrinology and Metabolism, All India Institute of Medical Sciences, New Delhi-29, India, Ph: 011-26546659, Mob: 9868397604, Fax: 011-26588641; Email: vivekapjyotsna@gmail.com

Received: 15 January 2014

Accepted: 20 February 2014

Published: 01 June 2014 in children with previously undiagnosed primary hyperparathyroidism. Conclusion: Genu valgum is a common skeletal deformity in children with primary hyperparathyroidism. Solitary parathyroid adenoma was identified in all reported cases and all underwent parathyroidectomy. Pubertal growth spurt seems to contribute to the occurrence of genu valgum in children with primary hyperparathyroidism.

Keywords: Genu valgum, Hypercalcemia, Hyperparathyroidism, Parathyroid adenoma, Technetium-99m sestamibi

\section{How to cite this article}

Ramkumar S, Kandasamy D, Vijay MK, Tripathi M, Jyotsna VP. Genu valgum and primary hyperparathyroidism in children. Int $\mathrm{J}$ Case Rep Images 2014;5(6):401-407.

doi:10.5348/ijcri-201455-CS-10041

\section{INTRODUCTION}

Primary hyperparathyroidism (PHPT) is one of the most common causes of hypercalcemia and metabolic bone disease in adults but it is a relatively uncommon disorder in children. Parathyroid adenomas are the most common cause of PHPT, other causes being four gland hyperplasia and rarely parathyroid carcinoma. Parathyroid adenoma can occur sporadically or as part of multiple endocrine neoplasia type 1 or type 2A (MEN-1/ MEN-2A). Primary hyperparathyroidism presenting with bony deformities such as genu valgum has rarely been reported in children its mechanism is not understood. We report two cases of hyperparathyroidism who presented to the endocrine outpatient department with genu valgum. 


\section{CASE SERIES}

Case 1: A 16-year-old boy was presented with symptoms of progressively increasing bowing of the legs for four years and bilateral leg pain for two years. He also had generalized arthralgia and polyuria. There was no history of recurrent fractures, recurrent vomiting, constipation or neck swelling. There was no past history of native treatment, the use of anti-tubercular or anti epileptic drugs, jaundice or renal problems. There was no family history of renal calculi, hypertension or multiple endocrine neoplasia (MEN) related disorders. His height, weight and body mass index were $177 \mathrm{~cm}, 67 \mathrm{~kg}$ and 21.38 $\mathrm{kg} / \mathrm{cm}^{2}$, respectively. Apart from genu valgum (Figure $1 \mathrm{~A})$, no other skeletal deformity was noted. He was in tanners stage 4. Hemogram, electrolytes, renal and liver functions test were normal. Serum prolactin was $\mathbf{1 1 . 2}$ (normal range 4.6-21.4 ng/mL) and serum albumin was $4.4 \mathrm{~g} / \mathrm{L}$. Radiological evaluation showed a brown tumor in the right proximal humerus (Figure $1 \mathrm{C}$ ). His base line calcium and vitamin D status are given in Table 1 . He was vitamin D deficient and after treatment of vitamin D deficiency, his hypercalcemia worsened and parathyroid hormone remained high. 24 hours urinary calcium excretion was $570 \mathrm{mg}$ per day. Ultrasonogram (Figure 1D) and Tc-99m MIBI (Figure 2) scan showed presence of a left inferior parathyroid adenoma. No thyroid nodule was seen in the neck ultrasonogram.

Case 2: A 13-year-old boy was presented with bowing of legs (Figure $3 \mathrm{~A}$ ) which was noted in last three months and was slowly progressive. Apart from myalgia, nausea and occasional abdominal pain, there was no other history of hypercalcemic symptoms, bone pain or fractures. There was no history of malabsorption, recurrent diarrhea, native treatment, antitubercular or antiepileptic drug intake, jaundice or renal problems. There was no family history of renal calculi, hypertension or MEN related disorders. His height, weight and body mass index were $154 \mathrm{~cm}, 50 \mathrm{~kg}$ and $21.08 \mathrm{~kg} / \mathrm{cm}^{2}$, respectively. Apart from genu valgum, no other skeletal deformity was noted. He was in tanner stage 2. His hemogram, electrolytes, renal and liver functions test were normal. Serum prolactin was 11.6 (normal range $4.6-21.4 \mathrm{ng} / \mathrm{mL}$ ) and serum albumin was $4.9 \mathrm{~g} / \mathrm{L}$. Radiological evaluation showed brown tumor in the distal femur and patella (Figure $3 \mathrm{~B}-\mathrm{C}$ ). Patient was initially suspected of rickets by a private practitioner and treated with injection arachitiol six lac units stat. Baseline calcium and vitamin are given in Table 1 . Similar to the first case, his hypercalcemia worsened and parathyroid hormone remained high. Urine showed calcium oxalate crystals. A 24-hour urinary calcium excretion was 520 mg per day. Ultrasonogram (Figure 3D) and (99m) Tcsestamibi (MIBI) scan (Figure 4) showed the presence of a right inferior parathyroid adenoma. No thyroid nodule was seen in neck ultrasonogram.

Both the children underwent resection of the parathyroid lesion. Biopsy in both cases was consistent with parathyroid adenoma. Cut section of both the

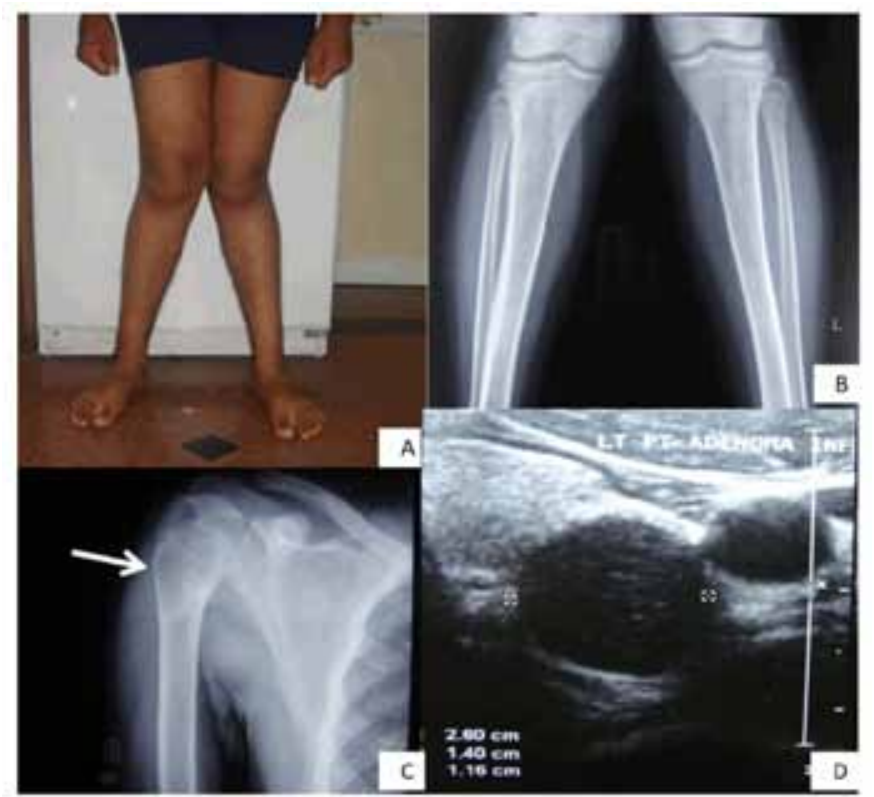

Figure 1: Case 1 (A) A clinical photograph of genu valgum, (B) Radiographs of bilateral knee, (C) Radiograph of right shoulder a well-defined lytic lesion in the proximal metaphysis of humerus (arrow) which in this setting is suggestive of brown tumor, (D) Axial ultrasound image showing a well-defined profoundly hypoechoic lesion $\left({ }^{*}\right)$ in the region of left parathyroid posterior to left thyroid lobe suggestive of parathyroid adenma.

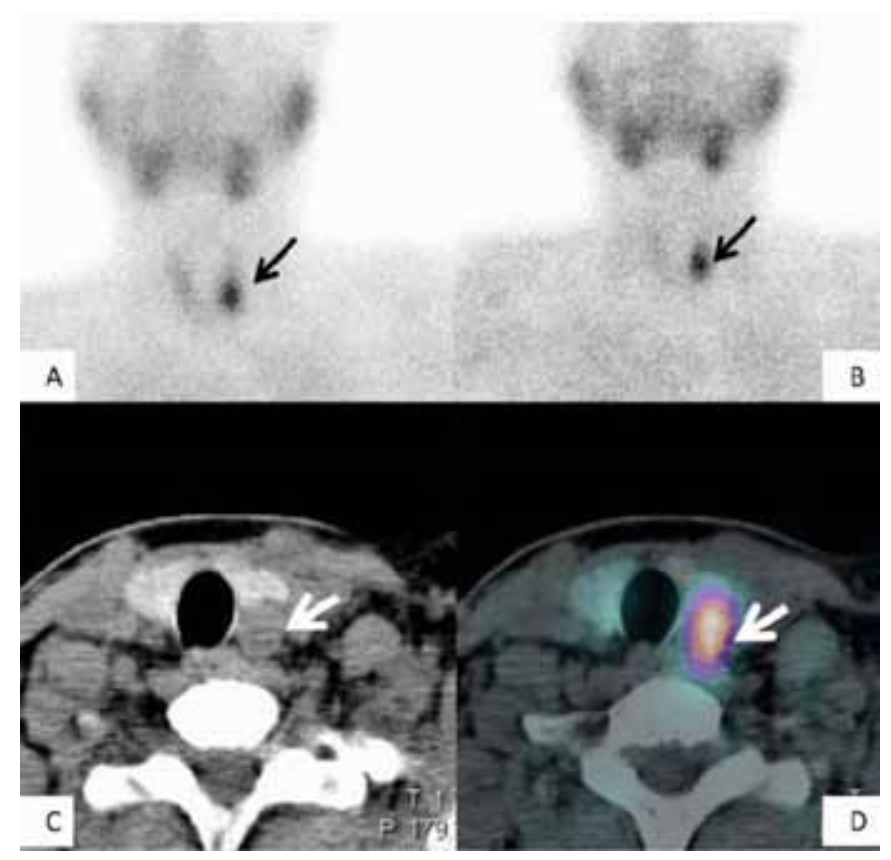

Figure 2: (99m) Tc-sestamibi (MIBI) scan and SPECT/CT images, (A) Early 10 minutes (B) Delayed 50 minutes (C) Focal localization of tracer in the left inferior polar region (thin arrow) and the corresponding transaxial plain computed tomography scan and (D) SPECT images showing tracer accumulation corresponding to a hypodense lesion in the lower pole of left lobe of thyroid (white arrow) (Case 1). 
Table 1: Serum total calcium, phosphate, alkaline phosphate, intact parathyroid hormone (iPTH) and 25-hydroxy vitamin D levels in both patients

\begin{tabular}{|c|c|c|c|c|c|}
\hline Patient & $\begin{array}{l}\text { Total Calcium } \\
\text { (mg\%) }\end{array}$ & Phosphate (mg\%) & $\mathbf{S A P}(I U / \mathbf{m L})$ & iPTH (pg/mL) & $\begin{array}{l}\text { 25-OH Vit-D (ng/ } \\
\text { mL) }\end{array}$ \\
\hline & \multicolumn{5}{|c|}{ At presentation } \\
\hline Case 1 & 11 & 3.7 & 2416 & 760.2 & 9.0 \\
\hline \multirow[t]{2}{*}{ Case 2} & 10.7 & 3.7 & 1001 & 1136 & 5.1 \\
\hline & \multicolumn{5}{|c|}{ After correction of vitamin D deficiency } \\
\hline Case 1 & 14.5 & 2.7 & 1099 & 569.9 & 21 \\
\hline \multirow[t]{2}{*}{ Case 2} & 14.7 & $4 \cdot 3$ & 1673 & 644 & 47.9 \\
\hline & \multicolumn{5}{|c|}{ After surgical removal of parathyroid adenoma } \\
\hline Case 1 & 8.4 & 2.0 & 646 & 23.9 & \\
\hline Case 2 & 8.2 & 2.7 & 970 & 24 & \\
\hline
\end{tabular}

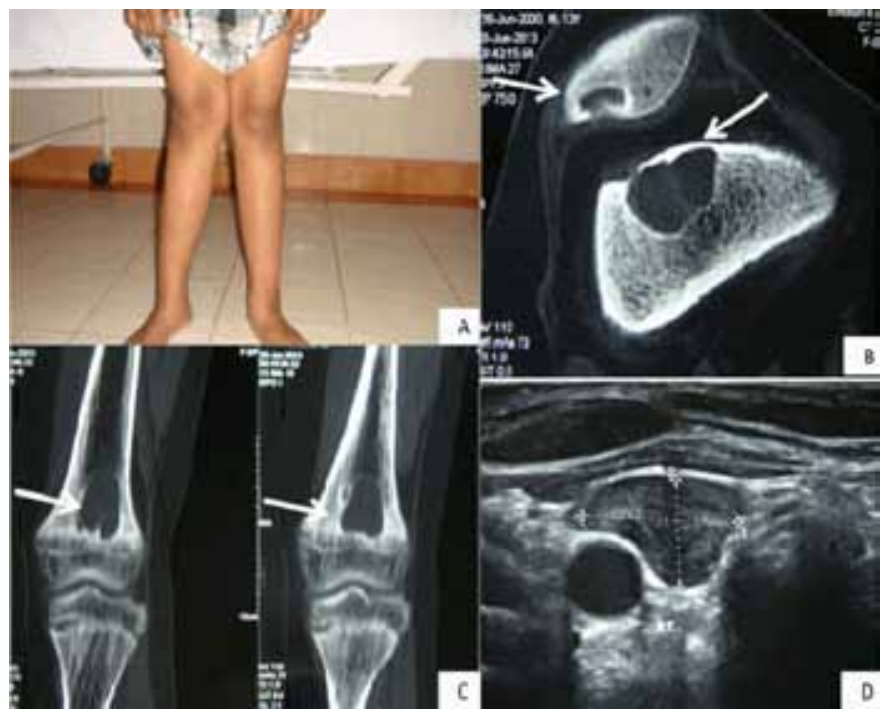

Figure 3: (A) A clinical photograph of genu valgum, (B, C) Computed tomography scan in axial and coronal plane showing well-defined lytic lesions in the lower end of femur and patella (arrow) suggestive of brown tumors (D) Ultrasound neck in axial plane $(3 \mathrm{D})$ showing a well-defined hypoechoic lesion $\left(^{*}\right)$ in the region of right parathyroid suggestive of right parathyroid adenoma (Case 2).

specimen showed grayish brown lobulated lesion surrounded by a thin connective tissue capsule. Microscopically, the tumor was encapsulated with a rim of compressed non-neoplastic parathyroid tissue at the periphery. The tumor was hypercellular and predominantly comprises chief cells (Figure 5). No nuclear atypia, mitotic activity or necrosis was identified. Postoperatively, both had symptomatic hypocalcemia secondary to transient hypoparathyroidism and were managed with calcium and calcitriol.

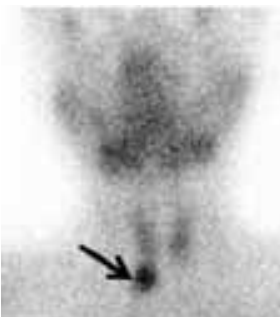

A
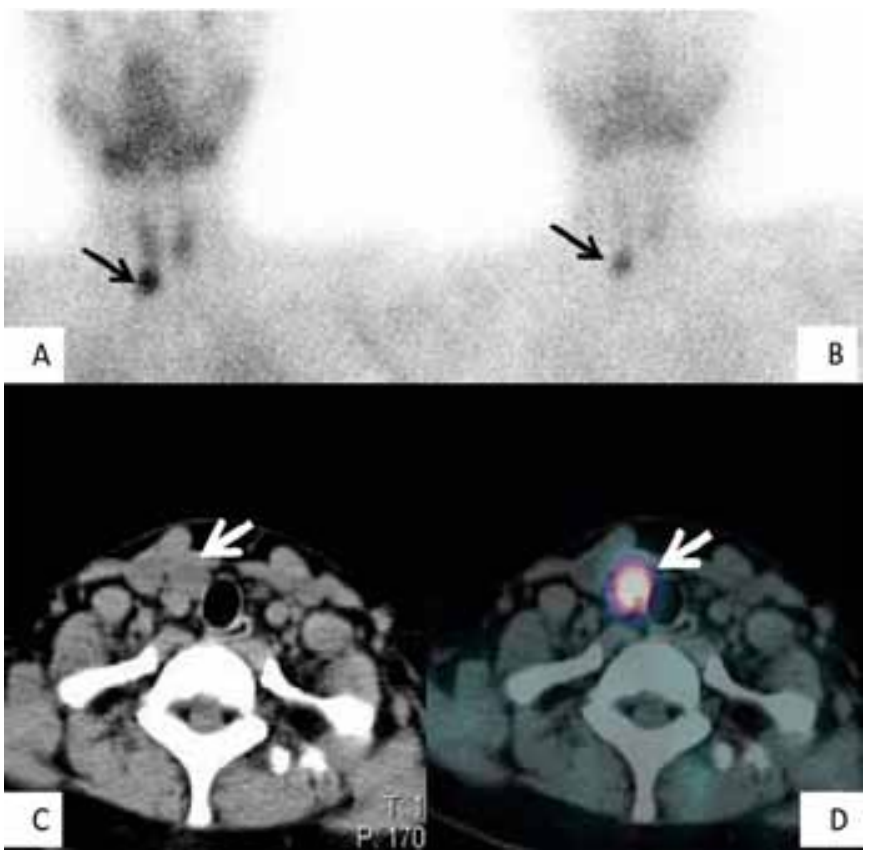

Figure 4: (99m) Tc-sestamibi (MIBI) scan and SPECT/CT images, (A) Early 10 minutes, (B) delayed 50 minutes, (C) focal localisation of tracer in the right inferior polar region (thin arrow), and the corresponding transaxial plain computed tomography scan and (D) SPECT images showing tracer accumulation corresponding to a hypodense lesion in the lower pole of right lobe of thyroid (white arrow) (Case 2).

\section{DISCUSSION}

Primary hyperparathyroidism in children is uncommon and usually presents with bone disease or renal stones [1-3]. The clinical spectrum of hyperparathyroidism in children is non-specific with vague signs and symptoms such as fatigue, anorexia, 

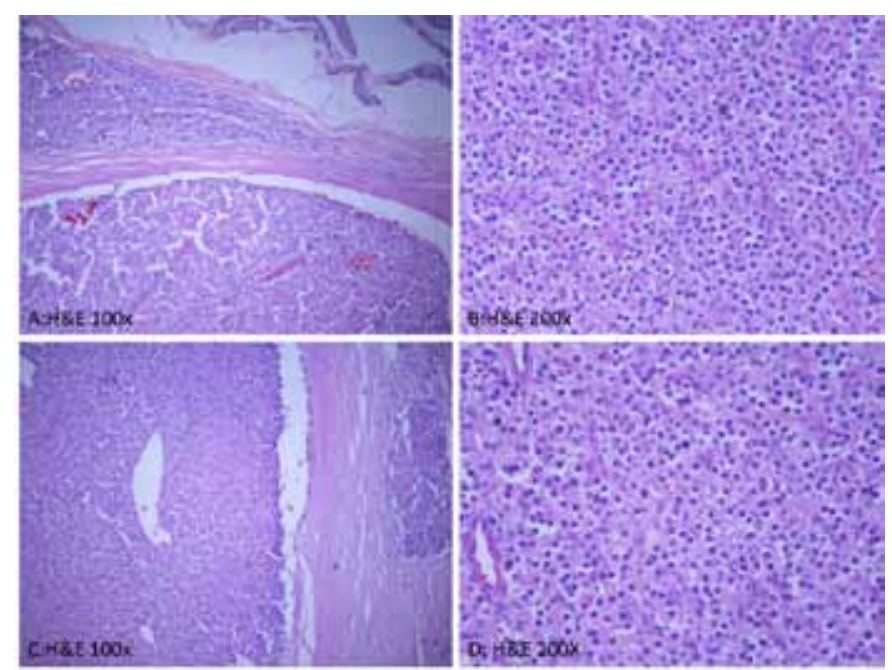

Figure 5: Microscopic section examined (Case 1 (A, B) and case 2 (C, D)) showing a well-encapsulated tumor predominantly comprises of chief cells. A compressed rim of normal parathyroid tissue is evident at the periphery.

nausea, vomiting, constipation, irritability and lack of concentration, which are attributed to hypercalcemia. Polyuria and polydipsia are seen in about 50\%. The level of 25-hydroxyvitamin D should be assessed in all patients suspected of having PHPT, and vitamin D deficiency should be cautiously corrected at the time it is detected. The Endocrine Society guidelines mention that the measurement of serum 25-hydroxy vitamin D levels be performed in all patients with PHPT and that correction of vitamin $\mathrm{D}$ depletion is warranted before other management decisions (medical or surgical) [4]. Genu valgum as a presenting feature of primary hyperparathyroidism is uncommon, though it is one of the skeletal deformities in children with primary hyperparathyroidism. To our knowledge, only 10 cases have been reported in literature. The clinical features, biochemical parameters and radiological findings in these cases are summarized in Table 2. Out of ten seven were girls and three were boys. Most of them had genu valgum as the presenting feature which definitely indicates an etiological link. All the 10 cases were due to a solitary parathyroid adenoma. Vitamin D deficiency can present with genu valgum and can also cause tertiary hyperparathyroidism. However, none of these cases were reported vitamin $\mathrm{D}$ deficient.

The two cases discussed here were boys and had presented with genu valgum as the primary complain. Similar to the published cases, both were detected to have solitary parathyroid adenomas. Both had normal serum prolactin level and ultrasonography of thyroid was normal, thus MEN-1/MEN-2A seems unlikely in these children. Although both cases were reported as vitamin D deficient, they did not have other features of rickets. Vitamin D deficiency alone is insufficient to explain the isolated occurrence of genu valgum in hyperparathyroidism in children. The second case described by us had evidence of brown tumor in the distal femur and patella. These tumors were not located in the growth plate regions it is unlikely that they could have resulted in genu valgum. Most of the cases described till date have presented during adolescence when it is expected that they would have a growth spurt. Bjernulf et al. reviewed 31 cases of primary hyperparathyroidism and reported three cases of genu valgum. They also reported one case of genu recurvatum and one case of skeletal deformity. Rapaport reported a single center experience of seven cases and genu valgum was present in two of these cases. We have earlier reported 3 cases of skeletal deformities in children with primary hyperparathyroidism from our Institute [6, 11]. First case reported by Menon et al. [6] had presented with genu valgum. Kataria et al. from our Institute had reported the other two cases; one with genu varum and another with deformities secondary to fractures [11]. The case described by Balch et al. [8], had presented at 21 years of age with hypercalcemic symptoms and was detected to have genu valgum at the time of presentation. Hyperparathyroidism like rickets causes bone demineralization and rarefaction and therefore could affect the remodeling process of growing long bones [10]. Though the exact mechanism for development of genu valgum in PHPT still needs to be defined, a possible explanation could be due to the direct effect of elevated parathyroid hormone on the growth plates during pubertal growth spurt.

\section{CONCLUSION}

Genu valgum is a rare presentation of PHPT in children. These children rarely manifest with other features of rickets. They have elevated parathyroid hormone levels with radiological features like brown tumors favoring hyperparathyroidism. Ultrasonogram and technetium 99M sestamibi scan are useful in localizing the parathyroid adenoma. Though the exact mechanism of genu valgum in these children with primary hyperparathyroidism needs to be elucidated, it is proposed that elevated parathyroid hormone levels may have a direct effect on the growth plates during pubertal growth spurt resulting in genu valgum.

\section{Author Contributions}

Ramkumar S - Substancial contribution to conception, design, Acquisition of data, Drafting the article, Revising it critically for important intellectual content, Final approval of the version to be published

Devasenathipathy Kandasamy - Substancial contribution to conception, design, Acquisition of data, Drafting and revising article critically for important radiology related content, Final approval of the version to be published.

Vijay MK - Substancial contribution to conception, design, Acquisition of data, Drafting the article and revising it critically for important Pathology related 


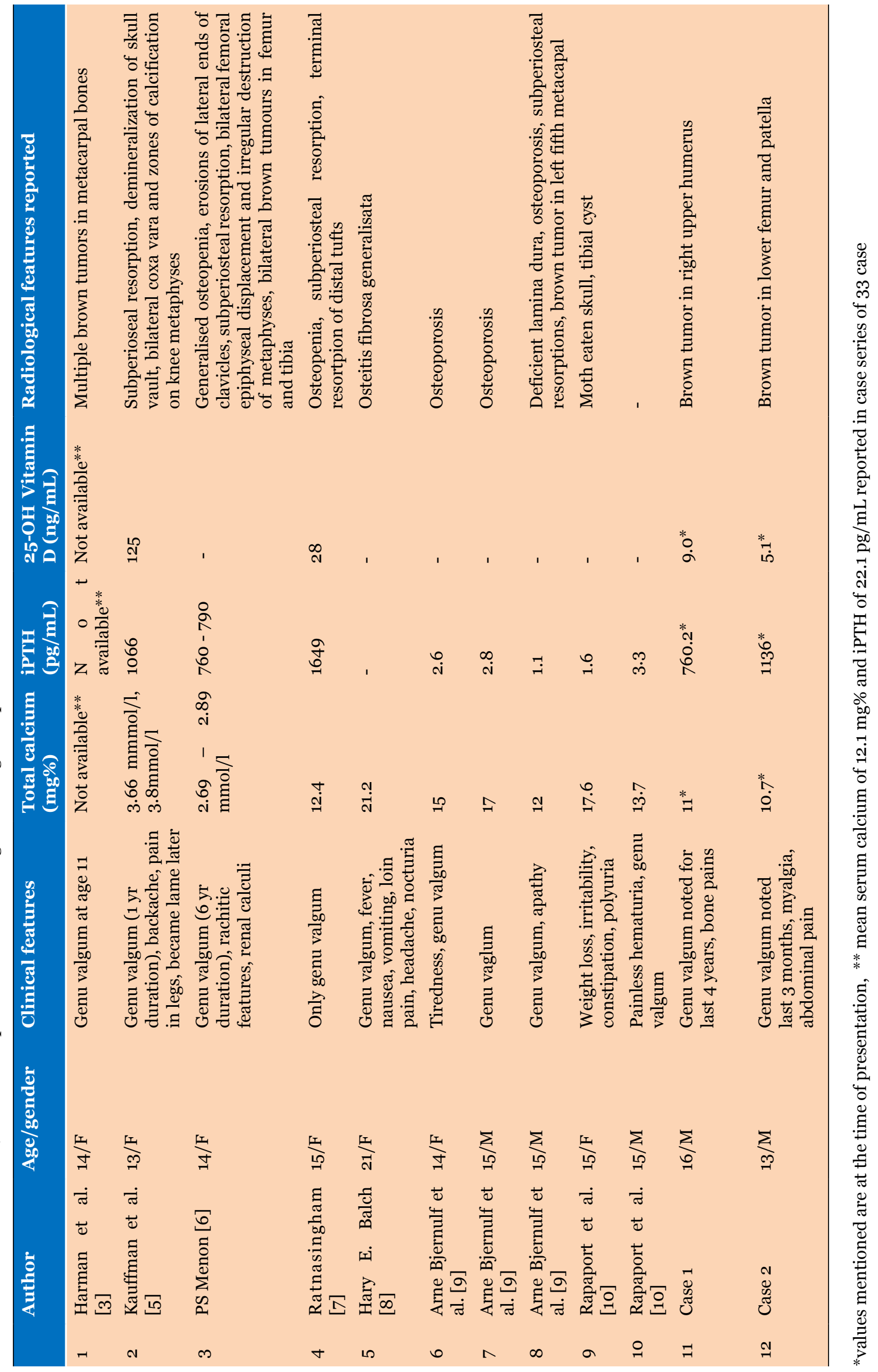


content, Final approval of the version to be published. Madhavi Tripathi - Substancial contribution to conception, design and acquisition of data, Drafting the article and revising it critically for important nuclear medicine related content, Final approval of the version to be published

Jyotsna VP - Substancial contribution to conception, design and acquisition of data, Drafting the article and revising it critically for important intellectual content, Final approval of the version to be published.

\section{Guarantor}

The corresponding author is the guarantor of submission.

\section{Conflict of Interest}

Authors declare no conflict of interest.

\section{Copyright}

(C) 2014 Ramkumar S et al. This article is distributed under the terms of Creative Commons Attribution License which permits unrestricted use, distribution and reproduction in any medium provided the original author(s) and original publisher are properly credited. Please see the copyright policy on the journal website for more information.

\section{REFERENCES}

1. Kollars J, Zarroug AE, van Heerden J, et al. Primary hyperparathyroidism in pediatric patients. Pediatrics 2005;115(4):974-80.

2. Lawson ML, Miller SF, Ellis G, Filler RM, Kooh SW. Primary hyperparathyroidism in a paediatric hospital. QJM 1996;89(12):921-32.

3. Harman CR, van Heerden JA, Farley DR, Grant CS, Thompson GB, Curlee K. Sporadic primary hyperparathyroidism in young patients: A separate entity? Arch Surg 1999;134(6):651-5.

4. Eastell R, Arnold A, Brandi ML, et al. Diagnosis of asymptomatic primary hyperparathyroidism: Proceedings of the third international workshop. J Clin Endocrinol Metab 2009;94(2):340-50.

5. Kauffmann C, Leroy B, Sinnassamy P, Carlioz H, Gruner M, Bensman A. A rare cause of bone pain in children: Primary hyperparathyroidism caused by adenoma. Arch Fr Pediatr 1993;50(9):771-4. [Article in French].

6. Menon PS, Madhavi N, Mukhopadhyaya S, Padhy AK, Bal CS, Sharma LK. Primary hyperparathyroidism in a 14 year old girl presenting with bone deformities. $\mathrm{J}$ Paediatr Child Health 1994;30(5):441-3.

7. Ratnasingam J, Tan AT, Vethakkan SR, et al. Primary hyperparathyroidism: A rare cause of genu valgus in adolescence. $\mathrm{J}$ Clin Endocrinol Metab 2013;98(3):869-70.

8. Balch HE, Spiegel EH, Upton AL, Kinsell LW, Hyperparathyroidism: Report of 2 cases with some relatively unusual manifestations. $\mathrm{J}$ Clin Endocrinol Metab 1953;13(6):733-8.
9. Bjernulf A, Hall K, Sjögren L, Werner I. Primary hyperparathyroidism in children. Brief review of the literature and a case report. Acta Paediatr Scand 1970;59(3):249-58.

10. Rapaport D, Ziv Y, Rubin M, Huminer D, Dinstan M. Primary hyperparathyroidism in children. J Pediatr Surg 1986;21(5):395-7.

11. Kataria R, Agarwala S, Mitra DK, et al. Primary hyperparathyroidism in children. Pediatr Surg Int 1996;11(5-6):374-7. 


\section{ABOUT THE AUTHORS}

Article citation: Ramkumar S, Kandasamy D, Vijay MK, Tripathi M, Jyotsna VP. Genu valgum and primary hyperparathyroidism in children. Int J Case Rep Images 2014;5(6):401-407.

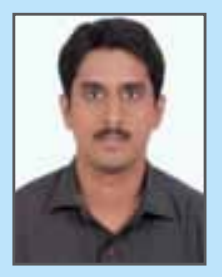

Ramkumar is Consultant Endocrinologist at Apollo Hospitals, Chennai, India. He earned the undergraduate degree MBBS from Thanjavur Medical College, Dr.MGR medical university, Chennai and postgraduate degree MD from Madras Medical College, Dr. MGR medical university, Chennai. He also obtained D.M Endocrinology Degree from All India Institute of Medical Sciences (AIIMS), New Delhi. He has published four research papers in national and international academic journals and authored two books. His research interests include pediatric endocrinology, pubertal disorders, disorders of sexual differentiation and pituitary disorders

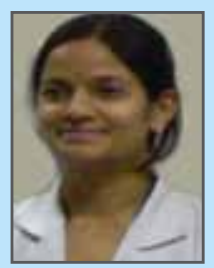

Madhavi Tripathi is Assistant Professor at the Department of Nuclear Medicine and PET, All India Institute of Medical Sciences, New Delhi. She earned the undergraduate degree MBBS from MKCG Medical College, Berhampur and postgraduate degree (MD) from SGPGIMS, Lucknow, India and a DNB in Nuclear Medicine from NBE, Delhi. She has published 45 research papers in national and international academic journals. Her research interests include functional imaging in movement disorders and dementia and use of non-FDG PET tracers in medicine. She intends to pursue a PhD degree in future.

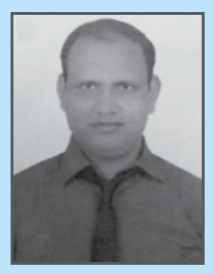

Vijay Maneesh is Senior Resident at Department of Pathology, All India Institute of Medical Sciences, New Delhi. He earned the undergraduate degree MBBS from S.M.S medical college, Jaipur and postgraduate degree MD Pathology from All India Institute of Medical Sciences, New Delhi. He has published 10 research papers in national and international academic journals and his research interest include renal pathology.

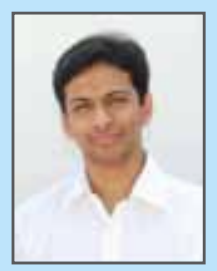

Devasenathipathy Kandasamy is Assistant Professor at Department of Radiodiagnosis (IRCH), All India Institute of Medical Sciences, New Delhi, India. He earned the undergraduate degree MBBS from Madras Medical College, Chennai and Postgraduate degree MD (Radiodiagnosis) From All India Institute of Medical Sciences, New Delhi, India. He has published 14 research papers in national and international academic journals and authored six books. His research interests include body imaging and interventions and imaging informatics.

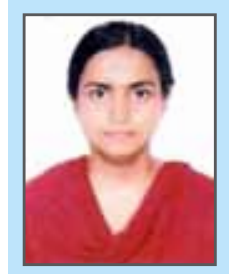

Viveka P. Jyotsna is Additional Professor at Department of Endocrinology at All India Institute of Medical Sciences, Delhi, India. She earned the undergraduate MBBS and postgraduate degree MD, DM form Institute of Medical Sciences, BHU, Varanasi. She has published 40 research papers in national and international academic journals. Her research interests include diabetes and neuroendocrinology,

Access full text article on other devices

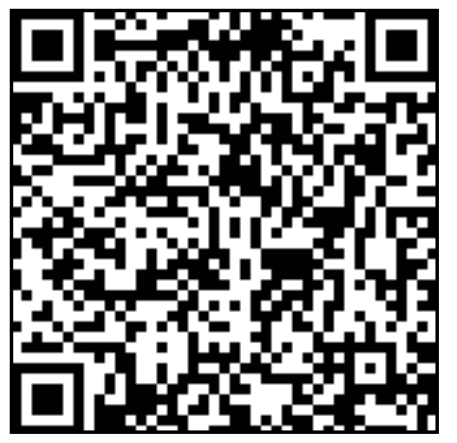

Access PDF of article on other devices

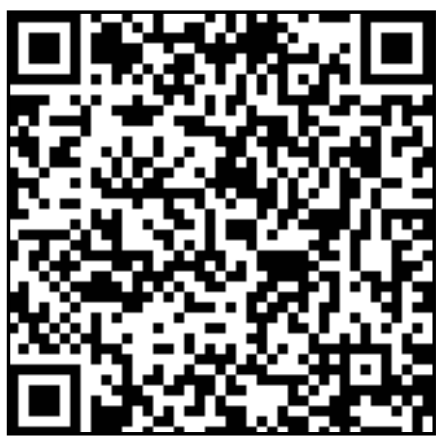

